\title{
Neutrophil gelatinase-associated lipocalin does not originate from the kidney during reperfusion in clinical renal transplantation
}

Arie Passov ${ }^{1 *} \mathbb{D}$, Minna Ilmakunnas ${ }^{2}$, Marjut Pihlajoki ${ }^{3}$, Kethe Hermunen ${ }^{4}$, Marko Lempinen ${ }^{4}$, Ilkka Helanterä4 , Villemikko Kailari ${ }^{5}$, Markku Heikinheimo ${ }^{3,6}$, Sture Andersson ${ }^{3}$ and Eero Pesonen ${ }^{2}$

*Correspondence:

arie.passov@hus.fi

${ }^{1}$ Division of Anaesthesiology, Department

of Anaesthesiology, Intensive Care and Pain Medicine,

University of Helsinki and Helsinki University Hospital, Topeliuksenkatu 5, PO BOX 266, 00029 HUS Helsinki, Finland Full list of author information is available at the end of the article

\begin{abstract}
Background: Acute Kidney Injury (AKI) is a common clinical complication. Plasma/ serum neutrophil gelatinase-associated lipocalin (NGAL) has been proposed as a rapid marker of AKI. However, NGAL is not kidney-specific. It exists in three isoforms (monomeric, homo-dimeric and hetero-dimeric). Only the monomeric isoform is produced by renal tubular cells and plasma NGAL levels are confounded by the release of all NGAL isoforms from neutrophils. Our aim was to investigate whether NGAL is released into blood from injured renal tubules.
\end{abstract}

Methods: Kidney transplantation $(n=28)$ served as a clinical model of renal ischaemic injury. We used ELISA to measure NGAL concentrations at 2 minutes after kidney graft reperfusion in simultaneously taken samples of renal arterial and renal venous blood. Trans-renal gradients (venous-arterial) of NGAL were calculated. We performed Western blotting to distinguish between renal and non-renal NGAL isoforms. Liver-type fatty acid binding protein (LFABP) and heart-type fatty acid binding protein (HFABP) served as positive controls of proximal and distal tubular damage.

Results: Significant renal release of LFABP [trans-renal gradient $8.4(1.7-30.0) \mathrm{ng} / \mathrm{ml}$, $p=0.005$ ] and HFABP [trans-renal gradient $3.7(1.1-5.0) \mathrm{ng} / \mathrm{ml}, p=0.003$ ] at 2 minutes after renal graft reperfusion indicated proximal and distal tubular damage. NGAL concentrations were comparable in renal venous and renal arterial blood. Thus, there was no trans-renal gradient of NGAL. Western blotting revealed that the renal NGAL isoform represented only $6 \%$ of the total NGAL in renal venous blood.

Conclusions: Ischaemic proximal and distal tubular damage occurs in kidney transplantation without concomitant NGAL washout from the kidney graft into blood. Plasma/serum NGAL levels are confounded by the release of NGAL from neutrophils. Present results do not support the interpretation that increase in plasma NGAL is caused by release from the renal tubules.

Keywords: Neutrophil-gelatinase associated lipocalin, Acute Kidney Injury, Kidney transplantation author(s) and the source, provide a link to the Creative Commons licence, and indicate if changes were made. The images or other third party material in this article are included in the article's Creative Commons licence, unless indicated otherwise in a credit line to the material. If material is not included in the article's Creative Commons licence and your intended use is not permitted by statutory regulation or exceeds the permitted use, you will need to obtain permission directly from the copyright holder. To view a copy of this licence, visit http:// creativecommons.org/licenses/by/4.0/. 


\section{Background}

Acute kidney injury (AKI) occurs frequently in hospitalized patients and is associated with increased mortality [1]. Currently, the diagnosis of AKI requires an increase of serum /plasma creatinine concentrations and/or decrease of urine output over time [2]. For faster diagnosis, neutrophil gelatinase-associated lipocalin (NGAL) has been proposed as early marker of renal injury [3, 4].

Experimental ischaemic kidney injury causes upregulation of NGAL gene expression and protein synthesis, which predominantly seems to occur in renal distal tubular epithelial cells [5-7]. Controversially, in graft biopsies at one hour after reperfusion in human kidney transplantation, NGAL protein accumulation is not found in the distal tubules but instead in the proximal tubular epithelial cells [8]. Since proximal tubular cells seem not to be the primary site of NGAL synthesis [6-8], NGAL detected in proximal tubules must originate from elsewhere. One potential source of NGAL in proximal tubular cells is glomerular filtration and subsequent tubular uptake of circulating NGAL [9]. In experimental studies, proximal tubular cells rapidly take up intravenously administered NGAL and degrade it in lysosomes, and do not release NGAL back into the circulation [7]. Furthermore, some reports suggest that tubular NGAL upregulation does not seem to translate into NGAL release into renal venous blood in experimental ischemic kidney injury $[10,11]$. Thus, evidence of NGAL back-leak from renal tubular cells into circulating blood remains elusive $[11,12]$.

In sepsis, cardiac surgery and exposure to nephrotoxic agents, AKI is associated with high plasma/serum concentrations of NGAL [13]. Likewise, plasma NGAL is elevated in patients with delayed graft function (DGF) after kidney transplantation [14, 15]. These associations are sometimes interpreted as direct evidence that circulating NGAL is derived from renal tubular cells, thus reflecting the severity of tubular injury [7, 14]. However, the presence of NGAL in systemic circulation in AKI and DGF does not imply that NGAL originates from the kidney. First, NGAL is not kidney specific. NGAL is produced also in liver, intestines and lungs [16-18]. Furthermore, neutrophils contain NGAL in their specific granules and release NGAL upon activation [19-21]. Consistent with this, in cardiac surgery, plasma levels of NGAL correlate with neutrophil activation marker lactoferrin [22]. Second, NGAL exists in three isoforms: monomeric (25 $\mathrm{kDa})$, homo-dimeric $(45 \mathrm{kDa})$ and hetero-dimeric $(145 \mathrm{kDa})[19,23]$. Mainly the monomeric and to a lesser extent the hetero-dimeric isoforms are produced by the renal tubular epithelial cells [20]. In contrast, neutrophils contain and release all of the isoforms [19-21]. Immunologic methods for NGAL detection, such as enzyme-linked immunosorbent assay (ELISA), that have been used in NGAL research, do not specifically detect the renal isoform [20,24]. Instead, they detect various combinations of NGAL isoforms based on the configuration of the antibody used in the method [20, 24]. Separating the isoforms by their molecular size with Western blotting revealed that the majority of circulating NGAL in cardiac surgery was of neutrophilic origin [22].

In contrast to the measurement of NGAL from the systemic circulation, kidney transplantation offers a time-controlled and specific clinical model of renal ischaemic injury with the possibility to measure the release of renal tubular injury biomarkers directly from the renal vein. Tubular damage is evident in up to $30 \%$ of the cadaveric renal grafts already during procurement, that is even before graft ischaemia [25, 26]. Furthermore, 
after cold ischaemia but before graft reperfusion, histological acute tubular lesions are present in approximately half of the cadaveric kidney grafts [27]. Graft reperfusion is associated with the washout of renal injury biomarkers and this washout can be detected by obtaining graft venous effluent blood shortly after reperfusion [28-30].

In the present study, we investigated whether NGAL is released from the kidney into circulation after ischaemic injury. Therefore, we measured NGAL concentrations in renal arterial and renal venous blood shortly after graft reperfusion and calculated the NGAL gradient across the renal circulation. In addition, to distinguish between renal and neutrophilic NGAL, the isoforms were separated by their molecular size with Western blotting. Proximal tubular damage biomarker liver-type fatty-acid binding protein (LFABP) and distal tubular damage biomarker heart-type fatty-acid binding protein (HFABP) [31, 32] served as controls for renal tubular damage.

\section{Methods}

\section{Patients}

The study protocol was approved by the Ethics Committee of Helsinki University Hospital (64/13/03/02/2015). Written informed consent was obtained from all patients before enrolment to the study. Twenty-eight adult patients suffering from end-stage renal disease receiving their first renal transplant from a brain-dead donor were prospectively recruited. Exclusion criteria were as follows: previous kidney transplantation, immunosuppression treatment protocol other than the local standard at the time of the study (cyclosporine A, mycophenolate mofetil, methyl prednisolone), significant prior HLAimmunization (panel reactive antibodies over 30\%), warfarin therapy, anti-platelet therapy other than aspirin, use of low molecular weight heparins or fondaparinux for other indication than haemodialysis during the last 2 weeks before surgery.

\section{Donors}

All grafts were retrieved from brain-dead heart beating donors. After determination of brain death, all donors received $1000 \mathrm{mg}$ of methyl prednisolone as a bolus. During organ procurement, shortly before organ perfusion, the donors received $30 \mathrm{~g}$ of mannitol and $25000 \mathrm{IU}$ of heparin intravenously. The kidneys were perfused with and preserved in University of Wisconsin solution.

\section{Anaesthesia and surgery}

Anaesthesia and surgery were conducted according to our institutions established clinical practice. Balanced inhalational anaesthesia was used. During reperfusion, mean arterial blood pressure was aimed at $80 \mathrm{mmHg}$ or above. In surgery, the graft venous anastomosis to the recipient's external iliac vein was completed first. Thereafter, the graft arterial anastomosis to the recipient's external iliac artery was completed. After reperfusion ureterocystostomy was done. Cold-ischaemia time was defined as the time from the onset of organ perfusion in the donor until declamping of the renal artery in the recipient (graft reperfusion). Warm-ischaemia time was defined as the time from the end of the cold-storage (transfer of the graft from storage-ice to the surgical field) until graft reperfusion. 


\section{Immunosuppression}

Immunosuppression consisted of the combination of cyclosporine A, mycophenolate mofetil and methylprednisolone. All patients received peroral cyclosporine A (5 mg/ $\mathrm{kg}$ ) and mycophenolate mofetil (1000 mg) preoperatively. After induction of anaesthesia, $125 \mathrm{mg}$ of methylprednisolone was given intravenously, followed by a second dose shortly before reperfusion.

\section{Blood samples}

Blood samples were drawn at two time points: (T1) after induction of anaesthesia, but before the start of the surgery; (T2) at 2 minutes after reperfusion. At T1, the blood sample was taken from the central venous catheter. At T2, the blood samples were taken across the graft circulation, that is from the arterial blood going into the transplant (the iliac artery) and the venous blood coming out of the transplant (the renal vein). The surgeons took the samples by vessel puncture with a $27 \mathrm{G}$ needle. The blood samples were drawn into $5 \mathrm{ml}$ syringes and transferred immediately into pyrogen free citrated vacuum tubes. Plasma was separated by centrifugation for $10 \mathrm{~min}$ at $2000 \mathrm{G}$ and stored in aliquots at $-80^{\circ} \mathrm{C}$.

\section{ELISA analyses}

Commercial enzyme-linked immunosorbent assay (ELISA) kits produced by Hycult Biotech (Uden, The Netherlands) were used for measurements of NGAL $(n=28)$, HFABP $(n=24)$ and LFABP $(n=26)$. LFABP was used as a positive control of proximal tubular damage and HFABP as a positive control of distal tubular damage [31, 32]. LFABP and HFABP analyses of a few patients are missing due to shortage of either iliac arterial or renal venous plasma samples (Table 3). All DGF patients had LFABP measurements, whereas HFABP measurements were missing from three DGF patients (Table 3).

\section{Western blot}

Non-reducing Western blotting $(n=25)$ was performed on all available samples, to detect plasma NGAL isoforms in preoperative blood sample and in renal venous blood at reperfusion. The method has been described in detail previously [22]. In brief, the samples were mixed 1:4 with Laemmli sample buffer. Protein content was quantified and $10 \mu \mathrm{g}$ of protein was separated by electrophoresis using Mini-Protean TGX Stain-Free gels (Bio-Rad Laboratories, CA, USA) and transferred onto a polyvinylidene fluoride membrane (Thermo Fisher Scientific, MA, USA). Primary antibody used was a polyclonal rabbit anti-HNL-NGAL (Diagnostics Development, Uppsala, Sweden) at dilution of 1:1000. Normalization and quantification of the protein band intensity were carried out using Image Lab 6.0 software.

\section{Clinical data}

The laboratory and clinical data were collected from the hospital electronic laboratory database and electronic health records. Delayed graft function was defined as a need for dialysis during the first week after transplantation [33]. T-cell mediated acute rejections 
during the first three months after transplantation were also recorded and defined as deterioration of the graft function associated with typical pathological findings in the graft biopsy.

\section{Statistical analysis}

Data are expressed as number of patients (percent) or median and interquartile range (IQR) when appropriate. Data were analysed with SPSS Version 23 (IBM Corp, Armonk, New York, USA) and GraphPad Prism 7.00 (GraphPad Software, La Jolla, California, USA). For calculation of trans-renal gradients of the biomarkers, the concentration in the arterial sample was subtracted from the concentration in the venous sample. Nonparametric tests were used for continuous data due to the small sample size. Thus, Wilcoxon signed rank test was used for paired comparisons and Mann Whitney $U$ test was used for testing differences between the groups where appropriate. Fisher's exact test was used for comparison of frequencies between the groups. $P$-values less than 0.05 were considered statistically significant.

\section{Results}

\section{Clinical data}

Transplants were retrieved from 25 brain-dead donors (Table 1). The median age of the donors was 60 (53-68) years. Recipient's characteristics and surgical procedure data are detailed in Table 2. All recipients were undergoing long-term dialysis treatment with either haemodialysis $(71 \%)$ or peritoneal dialysis $(29 \%)$, with a median duration on dialysis of 20 (11-38) months. The median graft cold-ischaemia time was 18.7 (15.2-21.7) hours and the median warm-ischaemia time was 54 (48-69) min. Delayed graft function (DGF) occurred in 6 recipients (21\%). Four recipients (14\%), two of whom had also DGF, suffered from acute T-cell-mediated rejection.

Table 1 Donor data

\begin{tabular}{lc}
\hline & ALL [N=25(100\%)] \\
\hline Age (years) & $60(53-68)$ \\
Male gender & $14(56 \%)$ \\
Body mass index $\left(\mathrm{kg} / \mathrm{m}^{2}\right)$ & $24(22-27)$ \\
Hypertension & \\
Diabetes & $7(28 \%)$ \\
Plasma creatinine at admission to ICU $(\mu \mathrm{mol} / \mathrm{l})$ & $1(4 \%)$ \\
Cause of brain-death & $53(47-62)$ \\
$\quad$ Subarachnoid haemorrhage & \\
$\quad$ Stroke & $6(24 \%)$ \\
$\quad$ Trauma & $8(32 \%)$ \\
Meningitis & $9(36 \%)$ \\
ICU stay (h) & $2(8 \%)$ \\
Time from declaration of brain death to organ perfusion in the donor $(\mathrm{h})$ & $35(22-81)$ \\
Kidney only donors & $9.4(7.0-14.0)$ \\
\hline
\end{tabular}

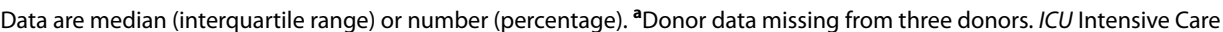
Unit 
Table 2 Recipient and transplant data

\begin{tabular}{|c|c|c|c|}
\hline & ALL $[N=28(100 \%)]$ & NO-DGF [N = $22(79 \%)]$ & $\operatorname{DGF}[N=6(21 \%)]$ \\
\hline Age (years) & $57(48-64)$ & $56(45-62)$ & $62(54-67)$ \\
\hline Male gender & $20(71 \%)$ & $14(64 \%)$ & $6(100 \%)$ \\
\hline Body mass index $\left(\mathrm{kg} / \mathrm{m}^{2}\right)$ & $25(23-28)$ & $25(23-27)$ & $25(21-30)$ \\
\hline \multicolumn{4}{|l|}{ Cause of ESRD } \\
\hline Polycystic kidney disease & $10(36 \%)$ & $8(36 \%)$ & $2(33 \%)$ \\
\hline Glomerulonephritis & $7(25 \%)$ & $4(18 \%)$ & $3(50 \%)$ \\
\hline Diabetes & $6(21 \%)$ & $6(27 \%)$ & $0(0 \%)$ \\
\hline Other & $5(18 \%)$ & $4(18 \%)$ & $1(16.7 \%)$ \\
\hline Time on dialysis (months) & $20(10-38)$ & $19(10-37)$ & $28(11-65)$ \\
\hline Haemodialysis & $20(71 \%)$ & $14(64 \%)$ & $6(100 \%)$ \\
\hline Peritoneal dialysis & $8(29 \%)$ & $8(36 \%)$ & $0(0 \%)$ \\
\hline Time on waiting list (months) & $11(4-26)$ & $10(3-24)$ & $22(4-37)$ \\
\hline \multicolumn{4}{|l|}{ Plasma creatinine $(\mu \mathrm{mol} / \mathrm{l})$ at } \\
\hline 1 week after transplant & $176(135-294)$ & $171(117-223)$ & $580(265-723)^{*}$ \\
\hline 1 month after transplant & $144(112-223)$ & $125(106-175)$ & $211(188-317)^{*}$ \\
\hline 3 months after transplant & $125(109-174)$ & $120(102-172)$ & $155(143-194) \dagger$ \\
\hline Cold ischaemia time (h) & $18.7(15.2-21.7)$ & $19.1(17.8-21.9)$ & $15.5(13.0-21.0)$ \\
\hline Warm ischaemia time $(h)^{\mathrm{a}}$ & $54(48-69)$ & $54(46-69)$ & $60(49-91)$ \\
\hline Rejection at 3 months & $4(14 \%)$ & $2(9 \%)$ & $2(33 \%)$ \\
\hline
\end{tabular}

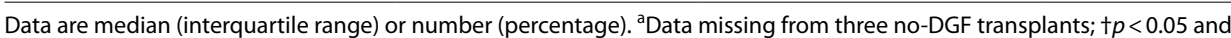
${ }^{*} p<0.01$ for DGF vs. NO-DGF. DGF Delayed Graft Function. ESRD end-stage renal disease

Table 3 Concentrations of NGAL, LFABP and HFABP

\begin{tabular}{|c|c|c|c|c|c|}
\hline & $\begin{array}{l}\text { Preoperative } \\
\text { venous blood }\end{array}$ & $\begin{array}{l}\text { Renal arterial } \\
\text { blood (ART) }\end{array}$ & $\begin{array}{l}\text { Renal venous } \\
\text { blood (VEN) }\end{array}$ & $\begin{array}{l}\text { Transrenal } \\
\text { gradient (VEN- } \\
\text { ART) }\end{array}$ & $\begin{array}{l}P \text {-value } \\
\text { (ART VS } \\
\text { VEN) }\end{array}$ \\
\hline \multicolumn{6}{|l|}{ NGAL (ng/ml) } \\
\hline $\operatorname{ALL}(N=28)$ & $71.4(53.9-90.0)$ & $64.9(46.5-83.4)$ & $62.3(47.3-86.7)$ & $0.5(-6.4-6.0)$ & 0.585 \\
\hline NO-DGF $(N=22)$ & $71.4(50.7-94.1)$ & $65.6(44.5-85.3)$ & $59.8(44.0-88.1)$ & $0.3(-4.5-5.3)$ & 0.78 \\
\hline $\mathrm{DGF}(N=6)$ & $70.6(56.9-81.6)$ & $64.9(60.8-69.7)$ & $63.2(56.9-90.3)$ & $2.7(-8.3-22.4)$ & 0.46 \\
\hline $\begin{array}{l}P \text {-VALUE (DGF VS } \\
\text { NO-DGF) }\end{array}$ & 0.89 & 0.98 & 0.37 & 0.494 & \\
\hline \multicolumn{6}{|l|}{ LFABP (ng/ml) } \\
\hline $\operatorname{ALL}(N=26)$ & $48.5(39.0-64.0)$ & $56.7(47.7-74.8)$ & $78.0(57.1-116.3)$ & $8.4(1.7-30.0)^{*}$ & $0.005^{*}$ \\
\hline NO-DGF $(N=20)$ & $43.5(36.6-61.6)$ & $56.3(44.7-66.3)$ & 73.5 (53.3-88.0) & $8.4(2.3-24.1)^{*}$ & $0.001^{*}$ \\
\hline $\mathrm{DGF}(N=6)$ & $56.0(48.3-104.1)$ & $77.5(54.5-125.6)$ & $103.3(68.7-131.4)$ & $16.7(-13.0-45.3)$ & 0.345 \\
\hline $\begin{array}{l}\text { P-VALUE (DGF VS } \\
\text { NO-DGF) }{ }^{\S \S}\end{array}$ & 0.11 & 0.22 & 0.083 & 0.836 & \\
\hline \multicolumn{6}{|l|}{ HFABP (ng/ml) } \\
\hline $\operatorname{ALL}(N=24)$ & $22.2(15.8-34.1)$ & $24.6(16.2-33.9)$ & $28.3(24.6-38.1)$ & $3.7(1.1-5.0)^{*}$ & $0.003^{*}$ \\
\hline NO-DGF $(N=21)$ & $21.6(15.7-28.5)$ & $23.2(15.5-30.2)$ & $27.8(24.5-35.3)$ & $3.7(1.5-5.2)^{*}$ & $0.0007^{*}$ \\
\hline $\mathrm{DGF}(N=3)$ & $36.4(35.5-65.1)$ & $34.0(33.8-66.8)$ & $38.4(35.8-62.4)$ & $-0.3(-6.7-2.1)$ & 0.59 \\
\hline $\begin{array}{l}\text { P-VALUE (DGF VS } \\
\text { NO-DGF) }\end{array}$ & $0.031^{*}$ & $0.041^{*}$ & 0.122 & 0.172 & \\
\hline
\end{tabular}

Data are median (interquartile range) for concentrations. All $p$-values are shown; ${ }^{\S}$ ART vs. VEN-Wilcoxon signed-rank test; ${ }^{\S}$ DGF vs. no-DGF Mann-Whitney $U$ test; Transrenal gradient (ART subtracted from VEN). * for statistically significant results $(p<0.05)$; NGAL neutrophil gelatinase-associated lipocalin, LFABP liver-type fatty-acid binding protein, HFABP heart-type fatty-acid binding protein, $A R T$ concentration in graft arterial blood, VEN concentration in graft venous blood, DGF Delayed Graft Function 


\section{Trans-renal concentration gradients}

The median preoperative LFABP concentration was 48.5 (39.0-64.0) $\mathrm{ng} / \mathrm{ml}$ (Table 3). At 2 minutes after reperfusion, LFABP levels were significantly higher in renal venous than arterial blood $(\mathrm{p}=0.005)$, indicating outflow of LFABP from the graft (Fig. 1, Table 3). The trans-renal gradient was $8.4(1.7-30.0) \mathrm{ng} / \mathrm{ml}$ (Fig. 2, Table 3).

The median preoperative HFABP concentration was $22.2(15.8-34.1) \mathrm{ng} / \mathrm{ml}$ (Table 3). At 2 minutes after reperfusion, HFABP levels were significantly higher in renal venous than arterial blood $(\mathrm{p}=0.003)$, indicating outflow of HFABP from the graft (Fig. 1, Table 3). The trans-renal gradient was $3.7(1.1-5.0) \mathrm{ng} / \mathrm{ml}$ (Fig. 2, Table 3).

The median preoperative NGAL concentration was $71.4(53.9-90.0) \mathrm{ng} / \mathrm{ml}$ (Table 3). At 2 minutes after reperfusion, NGAL levels in renal venous blood were comparable with the NGAL levels in arterial blood, indicating no outflow of NGAL from the graft into venous blood (Fig. 1, Fig. 2, Table 3). The trans-renal gradients of LFABP, HFABP and NGAL did not differ statistically between the DGF and no-DGF patients, although the median gradients of NGAL and LFABP tended to be higher in the patients with DGF (Table 3).

\section{Western blot analyses}

The Western blot analyses of six representative patients are shown in Fig. 3. The bands of all three NGAL isoforms were clearly visible in all samples. At 2 minutes after reperfusion, homo-dimeric $(45-\mathrm{kDa})$ and hetero-dimeric $(145-\mathrm{kDa})$ isoforms represented the majority of total NGAL in renal venous blood (Table 4). The potentially renal $25-\mathrm{kDa}$ isoform accounted for only $6 \%$ of the total NGAL in renal venous blood at 2 minutes after reperfusion (Table 4). The amount of $25-\mathrm{kDa}$ isoform in renal venous blood was lower compared with the amount in preoperative central venous blood ( $p=0.007$, Table 4). The distribution of NGAL isoforms was comparable in DGF and no-DGF patients (Fig. 4).

\section{Discussion}

The origin of circulating NGAL has been under debate [12, 22, 34]. We investigated renal release of NGAL into blood using clinical kidney transplantation as a model of renal ischaemic injury. After reperfusion, there was a significant renal release of proximal and distal tubular injury biomarkers LFABP and HFABP into renal venous blood. In contrast, we found no trans-renal release gradient of NGAL. In addition, Western blot analyses revealed that after reperfusion only $6 \%$ of NGAL in the renal venous blood was potentially of renal origin. Also, no increase in the renal venous $25-\mathrm{kDa}$ NGAL occurred after reperfusion. Our results do not support the theory of renal origin of circulating NGAL.

Our study showed significant release of LFABP and HFABP into renal venous blood after reperfusion indicating proximal and distal tubular damage. Both LFABP and HFABP are present in the cytosol of tubular epithelial cells [31], and have been used in several clinical settings as biomarkers of proximal and distal tubular damage, 


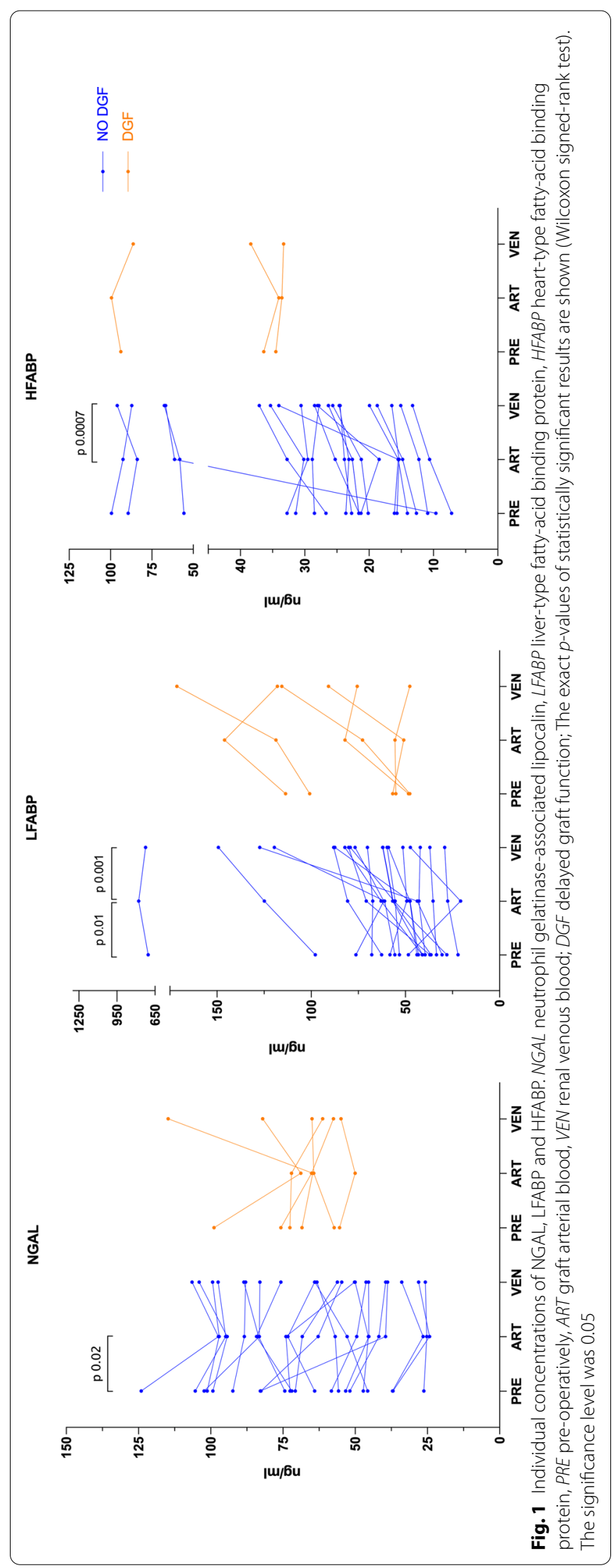




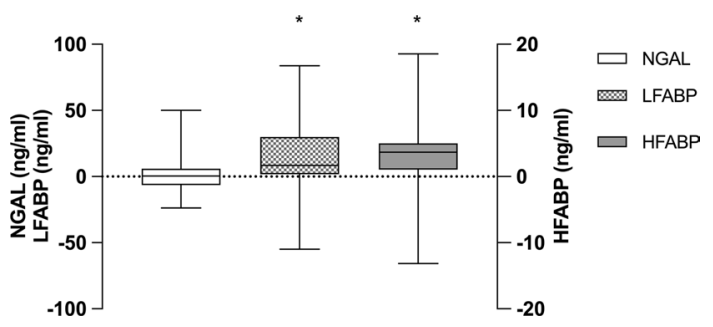

Fig. 2 Trans-renal gradients of NGAL, LFABP and HFABP. NGAL neutrophil gelatinase-associated lipocalin, $\angle F A B P$ liver-type fatty-acid binding protein, HFABP heart-type fatty-acid binding protein. ${ }^{*} p<0.01$ for renal venous blood vs. renal arterial blood. Trans-renal gradients were calculated as the concentration in arterial blood subtracted from the concentration in renal venous blood. The boxes represent median and interquartile-range and whiskers the lowest and the highest value

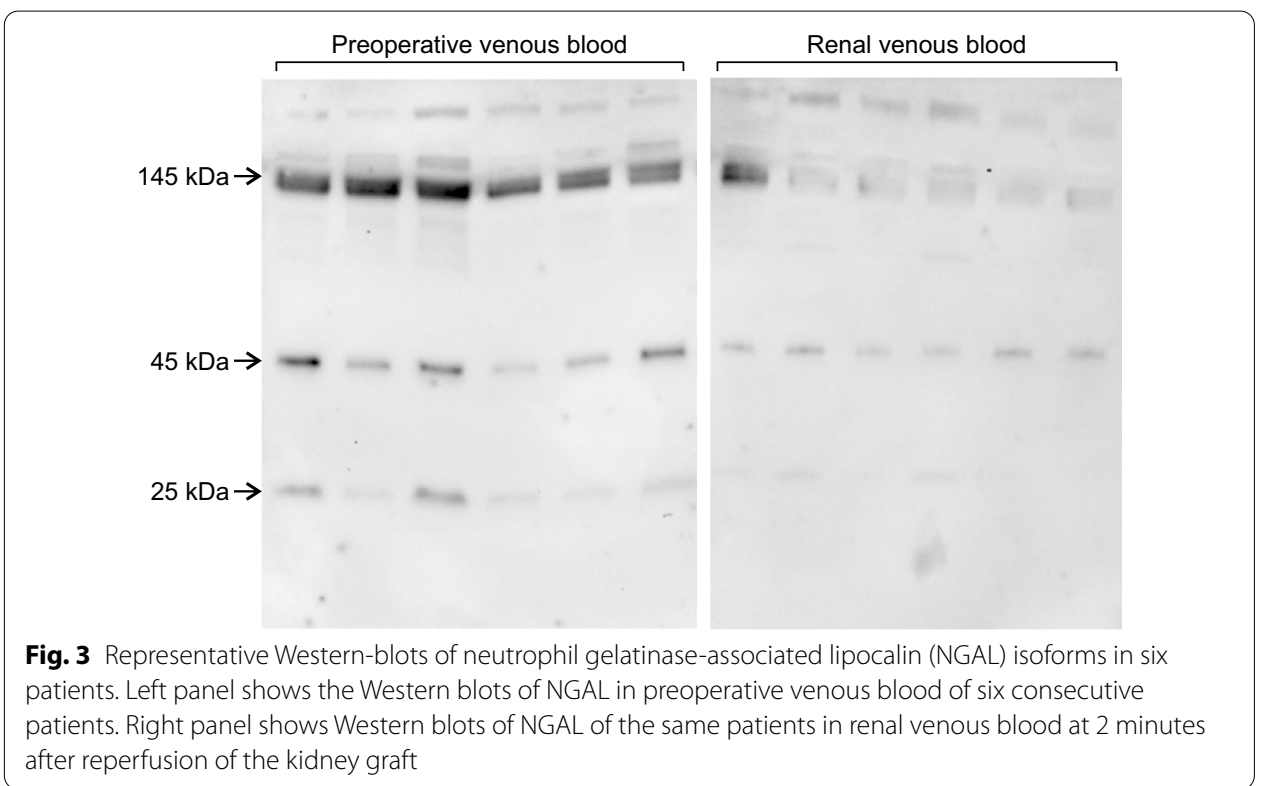

Table 4 Quantification of NGAL isomers by Western blotting

\begin{tabular}{lcc}
\hline & Preoperative central venous blood & Renal venous blood \\
\hline Monomeric, $25 \mathrm{kDa}(\%)$ & $9.8(6.4-15.4)$ & $6.1(3 .-9.1)^{*}$ \\
Homo-dimeric, 45 kDa (\%) & $25.4(15.3-38.7)$ & $32.8(17.1-40.8)$ \\
Hetero-dimeric, $145 \mathrm{kDa}(\%)$ & $63.4(48.1-70.2)$ & $58.9(51.5-76.1)$ \\
\hline
\end{tabular}

Data are median (interquartile range). ${ }^{*} p<0.01$ for preoperative central venous blood vs. renal venous blood (Wilcoxon signed-rank test). NGAL neutrophil gelatinase-associated lipocalin

respectively [32]. In contrast, we did not find NGAL release from the kidney grafts into blood as measured by ELISA. Our results are consistent with experimental studies, the results of which have been briefly reported in previous review articles: Despite local NGAL synthesis in tubular cells, no NGAL washout occurred from the kidney into renal venous blood [10, 11].

Interpretation of plasma NGAL concentrations measured by an ELISA assay is complex. Cultured human tubular epithelial cells produce mainly the $25-\mathrm{kDa}$ monomer, 


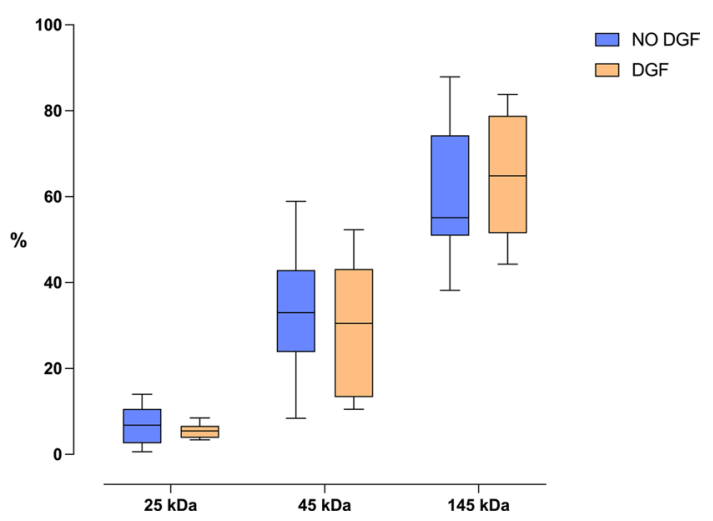

Fig. 4 Isoforms of NGAL in renal venous blood in patients with DGF and no-DGF. NGAL neutrophil gelatinase-associated lipocalin, DGF delayed graft function; The boxes represent median and interquartile-range and whiskers the lowest and the highest value

while neutrophils produce all of the isoforms [19-21]. To the best of our knowledge, there are no NGAL antibodies which are exclusively specific to the renal isoform [24]. Thus, ELISA assays usually detect various combinations of the isoforms [20, 24]. The ELISA kit used in our study detects all the isoforms. Therefore, it is possible, that the potential washout of the renal isoform could remain undetected with our ELISA assay. To distinguish between different isoforms, we performed Western blot analyses to separate the isoforms by their molecular size $[22,35]$. Renal venous sample contained only a median of $6 \%$ of the monomeric isoform, i.e. the isoform potentially derived from renal tubules. Furthermore, there was no increase in the proportion of the renal isoform in renal venous sample compared with the preoperative sample. These findings confirm the results of our ELISA assay. All in all, we did not find release of renal tubular NGAL into blood.

Although we did not find renal NGAL release into blood, we do not dispute the association of plasma NGAL levels with AKI and DGF. DGF is a clinical manifestation of acute tubular damage in renal transplantation [36]. Indeed, plasma NGAL concentrations after reperfusion are predictive of DGF $[14,15,37,38]$. However, the interpretation of renal origin of elevated plasma NGAL in DGF is complicated. In patients undergoing kidney transplantation, NGAL concentrations are elevated preoperatively [14] and often exceed the cutoff value of $165 \mathrm{ng} / \mathrm{ml}$ that represents the optimal combination of sensitivity/specificity (Youden index), established for AKI in non-transplantation patients [13]. In non-transplantation patients, NGAL values between the $95 \%$ sensitivity threshold and Youden index $(71 \mathrm{ng} / \mathrm{ml}-165 \mathrm{ng} / \mathrm{ml})$ are thought to reflect "grey zone" or increased risk of AKI $[4,13]$. By this definition, approximately half of our patients were in the "grey zone" already before transplantation. Only three of these patients ultimately developed DGF. High NGAL levels might be explained by the fact that in patients with end-stage renal disease NGAL, LFABP and HFABP values are chronically elevated and correlate with GFR [39-41]. Therefore, the NGAL cutoff values for kidney injury for non-transplantation patients are not applicable in transplantation setting. For kidney transplantation, higher NGAL cutoff values for DGF at $12 \mathrm{~h}$ post-transplantation [14] and on the post-operative day 1 [15] have been published with sensitivity and specificity in a range 
of $80-90 \%$. Yet, none of the studies have proposed cutoff levels for DGF within the sampling timeframe of early graft reperfusion in the present study. For LFABP the cutoff value in plasma that predicts DGF at post-operative day 1 with $80-90 \%$ specificity and sensitivity was $9 \mathrm{mg} / \mathrm{ml}$ [42]. All our patients exceeded this value already pre-operatively. To the best of our knowledge, there are no cutoff limits for HFABP in kidney transplantation to predict DGF. Taken together, the levels of plasma NGAL and fatty acid-binding proteins in patients with end-stage renal disease mostly exceed the cutoff values for AKI and are significantly affected by kidney function.

In non-transplantation patients with subclinical kidney injury GFR is compensated via a mechanism called the "renal functional reserve". Despite compensated GFR, these patients are at increased risk of dialysis, prolonged hospital and ICU-stay and higher mortality $[4,43]$. Deceased donors exhibit higher circulating NGAL levels than living related donors [37, 44], and therefore, subclinical kidney injury might be present in the grafts even before procurement. Speculatively, greater release of biomarkers during reperfusion could potentially indicate vulnerable grafts prone to develop DGF. Therefore, we compared the biomarker gradients between patients with DGF and no-DGF. The median gradients of LFABP and NGAL trended to be higher in DGF patients, but the difference was not statistically significant. A larger study is needed to reveal the differences between DGF and no-DGF patients.

The presence of NGAL in the granules of neutrophils poses another important confounding factor in the interpretation of plasma NGAL in patients undergoing kidney transplantation [19, 21]. Activated neutrophils release NGAL and other granule contents in response to inflammatory stimuli $[21,23]$. Systemic and local inflammation is inherent to cadaveric renal transplantation [28, 45-47]. Therefore, high plasma NGAL levels in DGF could be a result of neutrophil activation due to systemic and local inflammation instead of indicating damage of the tubular epithelial cells per se.

In contrast to plasma NGAL measurement that is affected by GFR [41], urine NGAL might be more reflective of histological tubular damage [48]. Urine NGAL is a good predictor of DGF at $24 \mathrm{~h}$ after transplantation with sensitivity of $88 \%$ and specificity of $81 \%$ [49]. Earlier measurements show clearly less accurate predictive power and low specificity [50]. Our focus was, however, specifically in the earliest events of the graft reperfusion. In this early time-window, measurement of urine NGAL is complicated and prone to several confounding factors. First, a substantial number of patients have ongoing or residual diuresis from the native kidneys. Second, some of the patients remain anuric after graft reperfusion, reflecting potentially severe graft injury and dysfunction. In these patients sampling is impossible. Third, some patients have significant haematuria after surgery, and urine NGAL may thus originate from activated neutrophils. This is an especially important confounding factor of Western blot analyses. Fourth, it may be necessary to flush the bladder catheters to avoid obstruction. Taken together, we decided to refrain from urine analyses, since it is impossible to conclude the origin of NGAL in urine immediately after reperfusion. Furthermore, urine NGAL cannot be measured in anuric patients, who potentially have the worst graft injury and function.

There are strengths and weaknesses in the present study. While the surgeons took the samples by vessel puncture directly from the iliac artery and renal vein, the samples reflect ingoing and outcoming blood in close proximity to the graft. LFABP and 
HFABP gradients verify that both proximal and distal tubular injury was present at the time of blood sampling. Still, blood samples drawn across the graft reflect concentration differences during only at a given single moment. This sets a limit for detection of renal release of a biomarker. We and others have shown that the washout of biomarkers is best detected during the first few minutes of reperfusion [29, 30, 47]. However, we cannot exclude potential release of NGAL at a later phase due to induced NGAL synthesis in the kidney. Of note, induced protein synthesis indicates cell viability rather than cell injury. Furthermore, experimental data suggest that instead of de novo protein synthesis, NGAL in proximal tubular cells may originate from the blood [7, 9]. In addition, both we and Mishra and co-workers did not investigate the graft biopsies before reperfusion [8]. Thus, it is unclear if NGAL was present in proximal or distal tubular cells at the time of blood sampling. Anyhow, we did not detect NGAL release from the graft despite concomitant proximal and distal tubular injury, as evidenced by renal LFABP and HFABP release. In addition, we acknowledge that our study was not powered to make firm conclusions about the difference between DGF and no-DGF patients or other clinical variables. Finally, we did not analyse urine samples because of potential bias related to sample collection and difficulties in the interpretation of the results in patients undergoing kidney transplantation.

\section{Conclusions}

In conclusion, proximal and distal tubular damage occurs in kidney transplantation without concomitant NGAL washout into renal venous blood after cold and warm ischaemia. Furthermore, circulating NGAL both preoperatively and at early reperfusion is confounded by neutrophils. The NGAL isoform potentially originating from the kidney represents only $6 \%$ of circulating NGAL after reperfusion. The proportion of the renal isoform did not increase at the time of reperfusion in the renal venous blood. The present results do not support the interpretation that increase in plasma NGAL is caused by the release from the renal tubules.

\section{Abbreviations}

AKI: Acute Kidney Injury; DGF: Delayed graft function; ELISA: Enzyme-linked immunosorbent assay; HFABP: Heart-type fatty acid binding protein; IQR: Interquartile range; LFABP: Liver-type fatty acid binding protein; NGAL: Neutrophil gelatinase-associated lipocalin.

\section{Acknowledgements}

Not applicable.

\section{Authors' contributions}

$\mathrm{MI}, \mathrm{EP}, \mathrm{AP}, \mathrm{ML}, \mathrm{IH}$ designed the study. Patients were recruited by $\mathrm{KH}, \mathrm{ML}$ and $\mathrm{H}$. $\mathrm{KH}$ and $\mathrm{ML}$ contributed significantly to collection of blood samples. Data was collected, analysed and interpreted by VK, MI, AP and EP. ELISA and Western blot analyses were conducted by AP, MP, EP, MH and SA. AP prepared the first draft of the manuscript and EP and MI were major contributors in writing the final version. All authors read and approved the final manuscript.

\section{Funding}

Open Access was funded by Helsinki University Library. This works was supported by Helsinki University Central Hospital EVO Grants (TYH2014116, TYH2015123) to Eero Pesonen and Finnish Society of Transplantation surgery personal grant to Arie Passov. The funders had no role in study design, data collection and analysis, decision to publish or preparation of the manuscript.

\section{Availability of data and materials}

The data sets used and analysed during the current study are available from the corresponding author on reasonable request. 


\section{Declarations}

\section{Ethics approval and consent to participate}

The study reported in this manuscript was performed in accordance with the Declaration of Helsinki. The study was approved by the Ethics Committee of Helsinki University Hospital (ethics committee reference number 64/13/03/02/2015). Written informed consent was obtained from all patients before enrolment to the study.

\section{Consent for publication}

Not applicable.

\section{Competing interests}

The authors declare that they have no competing interests.

\section{Author details}

'Division of Anaesthesiology, Department of Anaesthesiology, Intensive Care and Pain Medicine, University of Helsinki and Helsinki University Hospital, Topeliuksenkatu 5, PO BOX 266, 00029 HUS Helsinki, Finland. ${ }^{2}$ Division of Anaesthesiology, Department of Anaesthesiology, Intensive Care and Pain Medicine, University of Helsinki and Helsinki University Hospital, Haartmaninkatu 4, PO BOX 340, 00029 HUS Helsinki, Finland. ${ }^{3}$ Children's Hospital, Pediatric Research Center, University of Helsinki and Helsinki University Hospital, Stenbäckinkatu 9, PO BOX 347, FIN 00029 HUS Helsinki, Finland. ${ }^{4}$ Transplantation and Liver Surgery Clinic, Abdominal Center, University of Helsinki and Helsinki University Hospital, Haartmaninkatu 4, PO BOX 340, 00029 HUS Helsinki, Finland. ${ }^{5}$ Faculty of Medicine, University of Helsinki, PO BOX 63, 00014 Helsinki, Finland. ${ }^{6}$ Department of Pediatrics, St. Louis Children's Hospital, Washington University School of Medicine, One Children's Place, St. Louis, MO 63110, USA.

Received: 14 January 2021 Accepted: 11 November 2021

Published online: 22 November 2021

\section{References}

1. Rewa O, Bagshaw SM (2014) Acute kidney injury-epidemiology, outcomes and economics. Nat Rev Nephrol 10:193-207. https://doi.org/10.1038/nrneph.2013.282

2. Kellum JA, Lameire N, Aspelin P et al (2012) KDIGO clinical practice guideline for acute kidney injury. Kidney Int Suppl 2:1-138. https://doi.org/10.1038/kisup.2012.7

3. Mishra J, Dent C, Tarabishi R et al (2005) Neutrophil gelatinase-associated lipocalin (NGAL) as a biomarker for acute renal injury after cardiac surgery. Lancet 365:1231-1238. https://doi.org/10.1016/S0140-6736(05)74811-X

4. Albert C, Haase M, Albert A et al (2020) Biomarker-guided risk assessment for acute kidney injury: time for clinical implementation? Ann Lab Med 41:1-15. https://doi.org/10.3343/alm.2021.41.1.1

5. Mishra J, Ma Q, Prada A et al (2003) Identification of neutrophil gelatinase-associated lipocalin as a novel early urinary biomarker for ischemic renal injury. J Am Soc Nephrol 14:2534-2543. https://doi.org/10.1097/01.ASN.00000 88027.54400.C6

6. Paragas N, Qiu A, Zhang Q et al (2011) The Ngal reporter mouse detects the response of the kidney to injury in real time. Nat Med 17:216-223. https://doi.org/10.1038/nm.2290

7. Mori K, Lee HT, Rapoport D et al (2005) Endocytic delivery of lipocalin-siderophore-iron complex rescues the kidney from ischemia-reperfusion injury. J Clin Invest 115:610-621. https://doi.org/10.1172/JCI200523056

8. Mishra J, Ma Q, Kelly C et al (2006) Kidney NGAL is a novel early marker of acute injury following transplantation. Pediatr Nephrol 21:856-863. https://doi.org/10.1007/s00467-006-0055-0

9. Axelsson L, Bergenfeldt M, Ohlsson K (1995) Studies of the release and turnover of a human neutrophil lipocalin. Scand J Clin Lab Invest 55:577-588. https://doi.org/10.3109/00365519509110257

10. Schmidt-Ott KM, Mori K, Kalandadze A et al (2006) Neutrophil gelatinase-associated lipocalin-mediated iron traffic in kidney epithelia. Curr Opin Nephrol Hypertens 15:442-449. https://doi.org/10.1097/01.mnh.0000232886.81142. 58

11. Schmidt-Ott KM, Mori K, Li JY et al (2007) Dual action of neutrophil gelatinase-associated lipocalin. J Am Soc Nephrol 18:407-413. https://doi.org/10.1681/ASN.2006080882

12. Devarajan P (2010) Review: Neutrophil gelatinase-associated lipocalin: a troponin-like biomarker for human acute kidney injury. Nephrology 15:419-428. https://doi.org/10.1111/j.1440-1797.2010.01317.x

13. Albert C, Zapf A, Haase M et al (2020) Neutrophil gelatinase-associated lipocalin measured on clinical laboratory platforms for the prediction of acute kidney injury and the associated need for dialysis therapy: a systematic review and meta-analysis. Am J Kidney Dis 76:826-841. https://doi.org/10.1053/j.ajkd.2020.05.015

14. Bataille A, Abbas S, Semoun O et al (2011) Plasma neutrophil gelatinase-associated lipocalin in kidney transplantation and early renal function prediction. Transplantation 92:1024-1030. https://doi.org/10.1097/TP.0b013e3182 30c079

15. Hollmen ME, Kyllönen LE, Merenmies J, Salmela KT (2014) Serum neutrophil gelatinase-associated lipocalin and recovery of kidney graft function after transplantation. BMC Nephrol 15:123. https://doi.org/10.1186/ 1471-2369-15-123

16. Cowland JB, Sørensen OE, Sehested M, Borregaard N (2003) Neutrophil gelatinase-associated lipocalin is up-regulated in human epithelial cells by IL-1 $\beta$, but Not by TNF-a. J Immunol 171:6630-6639. https://doi.org/10.4049/jimmu nol.171.12.6630

17. Nielsen BS, Borregaard N, Bundgaard JR et al (1996) Induction of NGAL synthesis in epithelial cells of human colorectal neoplasia and inflammatory bowel diseases. Gut 38:414-420. https://doi.org/10.1136/gut.38.3.414 
18. Yoshikawa K, Iwasa M, Eguchi A et al (2017) Neutrophil gelatinase-associated lipocalin level is a prognostic factor for survival in rat and human chronic liver diseases. Hepatol Commun 1:946-956. https://doi.org/10.1002/hep4.1109

19. Kjeldsen L, Johnsen AH, Sengeløv H, Borregaard N (1993) Isolation and primary structure of NGAL, a novel protein associated with human neutrophil gelatinase. J Biol Chem 268:10425-10432

20. Cai L, Rubin J, Han W et al (2010) The origin of multiple molecular forms in urine of HNL/NGAL. Clin J Am Soc Nephrol 5:2229-2235. https://doi.org/10.2215/CJN.00980110

21. Kjeldsen L, Bainton DF, Sengeløv H, Borregaard N (1994) Identification of neutrophil gelatinase-associated lipocalin as a novel matrix protein of specific granules in human neutrophils. Blood 83:799-807

22. Passov A, Petäjä L, Pihlajoki M et al (2019) The origin of plasma neutrophil gelatinase-associated lipocalin in cardiac surgery. BMC Nephrol 20:182. https://doi.org/10.1186/s12882-019-1380-4

23. Xu SY, Carlson M, Engström A et al (1994) Purification and characterization of a human neutrophil lipocalin (HNL) from the secondary granules of human neutrophils. Scand I Clin Lab Invest 54:365-376

24. Cai L, Borowiec J, Xu S et al (2009) Assays of urine levels of HNL/NGAL in patients undergoing cardiac surgery and the impact of antibody configuration on their clinical performances. Clin Chim Acta 403:121-125. https://doi.org/ 10.1016/j.cca.2009.01.030

25. Moledina DG, Hall IE, Thiessen-Philbrook H et al (2017) Performance of serum creatinine and kidney injury biomarkers for diagnosing histologic acute tubular injury. Am J Kidney Dis 70:807-816. https://doi.org/10.1053/j.ajkd.2017. 06.031

26. Hall IE, Reese PP, Weng FL et al (2014) Preimplant histologic acute tubular necrosis and allograft outcomes. Clin J Am Soc Nephrol 9:573-582. https://doi.org/10.2215/CJN.08270813

27. Oberbauer R, Rohrmoser M, Regele H et al (1999) Apoptosis of tubular epithelial cells in donor kidney biopsies predicts early renal allograft function. J Am Soc Nephrol 10:2006-2013. https://doi.org/10.1681/ASN.V1092006

28. Snoeijs MGJ, Van Bijnen A, Swennen E et al (2011) Tubular epithelial injury and inflammation after ischemia and reperfusion in human kidney transplantation. Ann Surg 253:598-604. https://doi.org/10.1097/SLA.0b013e31820d9ae9

29. Snoeijs MG, Vink H, Voesten $\mathrm{N}$ et al (2010) Acute ischemic injury to the renal microvasculature in human kidney transplantation. Am J Physiol Renal Physiol 299:F1134-F1140. https://doi.org/10.1152/ajprenal.00158.2010

30. Turunen AJ, Lindgren L, Salmela KT et al (2008) Intragraft coagulation events and delayed graft function in clinical renal transplantation. Transplantation 85:693-699. https://doi.org/10.1097/TP.0b013e31816615d8

31. Maatman R, Vankuppevelt T, Veerkamp JH (1991) 2 Types of fatty acid-binding protein in human kidney - isolation, characterization and localization. Biochem J 273:759-766

32. Pelsers MM, a L, (2008) Fatty acid-binding protein as marker for renal injury. Scand J Clin Lab Invest Suppl 241:73-77. https://doi.org/10.1080/00365510802150133

33. Mallon DH, Summers DM, Bradley JA, Pettigrew GJ (2013) Defining delayed graft function after renal transplantation: Simplest is best. Transplantation 96:885-889. https://doi.org/10.1097/TP.0b013e3182a19348

34. Mårtensson J, Bellomo RR (2014) The rise and fall of NGAL in acute kidney injury. Blood Purif 37:304-310. https://doi. org/10.1159/000364937

35. Mårtensson J, Xu S, Bell M et al (2012) Immunoassays distinguishing between HNL/NGAL released in urine from kidney epithelial cells and neutrophils. Clin Chim Acta 413:1661-1667. https://doi.org/10.1016/j.cca.2012.05.010

36. Schröppel B, Legendre C (2014) Delayed kidney graft function: from mechanism to translation. Kidney Int 86:251258. https://doi.org/10.1038/ki.2014.18

37. Buemi A, Musuamba F, Frederic S et al (2014) Is plasma and urine neutrophil gelatinase-associated lipocalin (NGAL) determination in donors and recipients predictive of renal function after kidney transplantation? Clin Biochem 47:68-72. https://doi.org/10.1016/j.clinbiochem.2014.06.079

38. Cantaluppi V, Dellepiane S, Tamagnone M et al (2015) Neutrophil Gelatinase Associated Lipocalin is an early and accurate biomarker of graft function and tissue regeneration in kidney transplantation from extended criteria donors. PLoS ONE 10:1-19. https://doi.org/10.1371/journal.pone.0129279

39. Magnusson NE, Hornum M, Jørgensen KA et al (2012) Plasma neutrophil gelatinase associated lipocalin (NGAL) is associated with kidney function in uraemic patients before and after kidney transplantation. BMC Nephrol 13:8. https://doi.org/10.1186/1471-2369-13-822325322

40. Bjurman C, Petzold M, Venge P et al (2015) High-sensitive cardiac troponin, NT-proBNP, hFABP and copeptin levels in relation to glomerular filtration rates and a medical record of cardiovascular disease. Clin Biochem 48:302-307. https://doi.org/10.1016/j.clinbiochem.2015.01.008

41. Donadio C (2014) Effect of glomerular filtration rate impairment on diagnostic performance of neutrophil gelatinase-associated lipocalin and B-type natriuretic peptide as markers of acute cardiac and renal failure in chronic kidney disease patients. Crit Care 18:1-12. https://doi.org/10.1186/cc13752

42. Kawai A, Kusaka M, Kitagawa F et al (2014) Serum liver-type fatty acid-binding protein predicts recovery of graft function after kidney transplantation from donors after cardiac death. Clin Transplant 28:749-754. https://doi.org/ $10.1111 /$ ctr.12375

43. Haase M, Devarajan P, Haase-fielitz A et al (2016) The outcome of neutrophil gelatinase-associated lipocalin (ngal)positive subclinical acute kidney injury: a multicenter pooled analysis of prospective studies. J Am Coll Cardiol 57:1752-1761. https://doi.org/10.1016/j.jacc.2010.11.051.The

44. Hollmen ME, Kyllönen LE, Inkinen KA et al (2011) Deceased donor neutrophil gelatinase-associated lipocalin and delayed graft function after kidney transplantation: A prospective study. Crit Care 15:R121. https://doi.org/10.1186/ cc10220

45. Watts RP, Thom O, Fraser JF (2013) Inflammatory signalling associated with brain dead organ donation: from brain injury to brain stem death and posttransplant ischaemia reperfusion injury. J Transplant 2013:1-19. https://doi.org/ $10.1155 / 2013 / 521369$

46. Turunen AJ, Lindgren L, Salmela KT et al (2004) Association of graft neutrophil sequestration with delayed graft function in clinical renal transplantation. Transplantation 77:1821-1826. https://doi.org/10.1097/01.tp.0000122231. 43653.cc 
47. Turunen AJ, Fernández JA, Lindgren L et al (2005) Activated protein C reduces graft neutrophil activation in clinical renal transplantation. Am J Transplant 5:2204-2212. https://doi.org/10.1111/j.1600-6143.2005.00994.x

48. Vanmassenhove J, Vanholder R, Nagler E, Van Biesen W (2013) Urinary and serum biomarkers for the diagnosis of acute kidney injury: an in-depth review of the literature. Nephrol Dial Transplant 28:254-273. https://doi.org/10. 1093/ndt/gfs380

49. Li YM, Li Y, Yan L et al (2019) Comparison of urine and blood NGAL for early prediction of delayed graft function in adult kidney transplant recipients: a meta-analysis of observational studies. BMC Nephrol 20:1-10. https://doi.org/ 10.1186/s12882-019-1491-y

50. Cui LY, Zhu X, Yang S et al (2015) Prognostic value of levels of urine neutrophil gelatinase-associated lipocalin and interleukin-18 in patients with delayed graft function after kidney transplantation. Transplant Proc 47:2846-2851. https://doi.org/10.1016/j.transproceed.2015.10.042

\section{Publisher's Note}

Springer Nature remains neutral with regard to jurisdictional claims in published maps and institutional affiliations.

\section{Submit your manuscript to a SpringerOpen ${ }^{\circ}$} journal and benefit from:

- Convenient online submission

- Rigorous peer review

- Open access: articles freely available online

- High visibility within the field

- Retaining the copyright to your article

Submit your next manuscript at $\gg$ springeropen.com 